\title{
Phase-wise enhanced voltage support from electric vehicles in a Danish low-voltage distribution grid
}

\author{
Knezovic, Katarina; Marinelli, Mattia
}

Published in:

Electric Power Systems Research

Link to article, DOI:

10.1016/j.epsr.2016.06.015

Publication date:

2016

Document Version

Peer reviewed version

Link back to DTU Orbit

Citation (APA):

Knezovic, K., \& Marinelli, M. (2016). Phase-wise enhanced voltage support from electric vehicles in a Danish low-voltage distribution grid. Electric Power Systems Research, 140, 274-283.

https://doi.org/10.1016/j.epsr.2016.06.015

\section{General rights}

Copyright and moral rights for the publications made accessible in the public portal are retained by the authors and/or other copyright owners and it is a condition of accessing publications that users recognise and abide by the legal requirements associated with these rights.

- Users may download and print one copy of any publication from the public portal for the purpose of private study or research.

- You may not further distribute the material or use it for any profit-making activity or commercial gain

- You may freely distribute the URL identifying the publication in the public portal

If you believe that this document breaches copyright please contact us providing details, and we will remove access to the work immediately and investigate your claim. 


\title{
Phase-wise enhanced voltage support from electric vehicles in a Danish low-voltage distribution grid
}

\author{
Katarina Knezović* , Mattia Marinelli \\ Center for Electric Power and Energy, Department of Electrical Engineering, Technical University of Denmark, Denmark
}

\section{A R T I C L E I N F O}

\section{Article history:}

Received 23 September 2015

Received in revised form 1 March 2016

Accepted 9 June 2016

Available online $\mathrm{xxx}$

\section{Keywords:}

Electric vehicles

Reactive power control

Unbalanced distribution grid

Voltage support

\begin{abstract}
A B S T R A C T
High deployment of electric vehicles (EVs) imposes great challenges for the distribution grids, especially in unbalanced systems with notable voltage variations which detrimentally affect security of supply. On the other hand, with development of Vehicle-to-Grid technology, EVs may be able to provide numerous services for grid support, e.g., voltage control. Implemented electronic equipment will allow them to exchange reactive power for autonomous voltage support without communicating with the distribution system operator or influencing the available active power for primary transportation function. This paper proposes a voltage dependent EV reactive power control and quantifies its impact on a real Danish low-voltage grid. The observed network is a heavily unbalanced three-phase four-wire grid modeled in Matlab SimPowerSystems based on real hourly measurement data. Simulations are performed in order to evaluate phase-to-neutral voltage support benefits as well as to address neutral-to-ground values, active power losses and the unbalances at the same time. The analysis shows that reactive power support both raises minimum phase-to-neutral voltage magnitudes and improves voltage dispersion while the energy losses are not notably increased. Further on, since the control is voltage dependent, provided reactive power is unequal among the phases leading to greater support on heavily loaded phases and decreased unbalances caused by residential consumption. Hence, implementation of such a phase-wise enhanced voltage support could defer the need for grid reinforcement in case of large EV penetration rates, especially in highly unbalanced networks.
\end{abstract}

(c) 2016 Elsevier B.V. All rights reserved.

\section{Introduction}

Distribution system operators (DSOs) have historically designed and operated their networks in order to follow a predicted demand with single-direction power flow only. Nowadays, due to increased share of renewable energy resources, DSOs are confronted with changes in the low-voltage grid operation [1]. Additionaly, since the market share of electric vehicles (EVs) is expected to grow significantly in the following years, even greater system complexity is imposed [2,3]. Danish Energy Association predicts 47,000 EVs in Denmark by 2020 in a moderate penetration scenario [4] meaning that distribution networks will have to cope with great increase in consumption and overall voltage degradation, especially in unbalanced systems where voltage quality is already decreased.

Unlike in other European countries, the three-phase connection is not reserved only for industrial consumers in Denmark, but it is

\footnotetext{
* Corresponding author. Tel.: +45 30585492.

E-mail addresses: kknez@elektro.dtu.dk (K. Knezović), matm@elektro.dtu.dk (M. Marinelli).
}

also available for residential customers. Distribution system operators experience high unbalances in the semi-urban areas where more loads are eventually connected to phase $a$ due to the lack of regulation for per phase load connection [5]. Uncontrolled EV charging in such grids may result in violation of the minimum voltage boundary followed by the need for grid reinforcement. As an economic alternative, different EV charging strategies can be used for supporting the grid as well as providing various flexibility services.

An extensive amount of research has been made on coordinated EV charging proving that such concept can be used for lowering the impact on the power system [6] or providing ancillary services such as frequency control [7]. Most of these strategies require an aggregator to coordinate larger amount of EVs and, if possible, offer their services to the power system operators. However, high local EV concentrations may occur before significant penetration rates occur on the higher level. Taking into account that residential EV charging highly impacts the power profile, voltage magnitudes and voltage unbalances, different approaches are considered in order to alleviate these adverse effects and make the grid compliant with existing standards. In order to integrate electric vehicles in the distribution 
grid, both centralized and decentralized charging strategies have been explored in the literature. Comparison of such two charging strategies has been presented in [8,9]. Centralized algorithm leads to the least cost solution and is easily extended to a hierarchical scheme, but requires great communication infrastructure for information exchange. On the other hand, decentralized control provides similar results to the centralized one, both in terms of cost and robustness against forecast errors. This would seem to favor decentralized control since it is based on local measurements and does not require additional communication infrastructure. However, the drawback is charging simultaneity since all controllers would respond instantaneously to the measurements which could eventually lead to instability in some cases [10].

It is shown across a variety of studies that centralized EV control reduces losses, improves voltage stability and performs peak shaving or congestion control [11-14]. In addition to linear optimization methods, model predictive control is investigated for scheduling EV charging with various network constraints [15]. On the contrary, decentralized voltage dependent charging strategy which requires only local voltage measurement is discussed in [16]. EV charging power can also be modulated in order to compensate for the voltage unbalances [17], but such an autonomous procedure is possible only for three-phase charging since the single-phase charger has solely the voltage measurement of the phase to which the EV is connected and therefore, does not have any information on the voltage unbalances.

The impact of controlled EV charging on voltage profiles and unbalances has been investigated mainly by modulating the active power which influences the time needed for full charge and consequently, the user comfort. On the contrary, reactive power control (RPC) from electric vehicles has scarcely been discussed in the literature. Such reactive power compensation can be used for grid support and mitigating induced voltage issues, both while vehicles are charging, and discharging in Vehicle-to-Grid mode [18]. Balancing the phases by reactive power provision has been discussed in [19] where centralized control is used for scheduling the vehicles located on different phases, but this approach requires additional communication infrastructure. Decentralized approach, more precisely, autonomous reactive power control based on droop control has been investigated in [20-22], but only in the case of a balanced system. The reactive power support in an unbalanced network has been investigated in [23]. Despite showing that capacitive load behavior in $\mathrm{EV}$ chargers has beneficial impact on the voltage, this approach assumes a fixed power factor for all vehicles regardless of the their connection phase which may not be good enough for high EV penetration rates in case of highly unbalanced networks.

\subsection{Objectives}

To the authors' knowledge, phase-wise enhanced voltage support from electric vehicles has not been extensively discussed in the literature so far. Not only does such a control provide voltage support while vehicles are charging, it also provides unequal reactive power on different phases leading to greater support on highly loaded phases and partial mitigation of unbalances caused by other loads. Hence, this paper investigates the impact of voltage dependent EV reactive power control on a residential low-voltage network by conducting unbalanced three-phase load flow, and evaluating voltage deviations and several unbalance factors. The modeled network represents a typical Danish semi-urban feeder with high penetration of photovoltaic installations where hourly consumption and production data are available for individual units. Furthermore, the paper compares the phase-to-neutral along with neutral-to-ground voltage benefits at the expense of potential increased currents and power losses aiming to assess the grid impact as well as the need for including such a control in future grid compliance regulations to allow better EV integration.

This paper is organized as follows. Section 2 presents the unbalance indicators used for evaluating the results, and briefly recalls the standards regarding the voltage power quality as the main motivation for presented voltage support. In Section 3, the applied methodology has been presented, whereas the test case with the description of conducted scenarios is given in Section 4. Finally, the results are discussed in Section 5 followed by the conclusion in Section 6.

\section{Unbalance indicators}

Contrary to other disturbances in the power system for which the performance is evident for the ordinary customers, unbalance belongs to those disturbances whose perceptible effects are produced in the long run. Unsymmetrical consumption and production lead to voltage and current unbalances which imply greater power losses, interference with the protection systems, components' performance degradation and overheating possibly to the pointof-burnout. To calculate the unbalanced voltages and currents in three-phase systems, symmetrical components are generally employed. The voltage unbalance can be decomposed into a direct sequence voltage, an inverse sequence voltage and a zero sequence voltage, with the relationship between the symmetrical sequence systems and the initial system as follows:

$\left[\begin{array}{l}U_{\text {direct }} \\ U_{\text {inverse }} \\ U_{\text {zero }}\end{array}\right]=\frac{1}{3}\left[\begin{array}{ccc}1 & 1 & 1 \\ 1 & \alpha & \alpha^{2} \\ 1 & \alpha^{2} & \alpha\end{array}\right]\left[\begin{array}{c}U_{a} \\ U_{b} \\ U_{c}\end{array}\right]$

where $\alpha=e^{j 2 \pi / 3}$. The same definition can be applied for defining the current direct, inverse and zero component.

For ensuring that electric appliances are operated in a safe manner, the European standard EN50160 [24] defines acceptable limits for several grid parameters. More precisely, the standard defines the limits for rms phase-to-neutral voltage magnitude $\left(\left|U_{p n}\right|\right)$ and the voltage unbalance factor (VUF) as follows:

$0.9 U_{\text {nom }} \leq\left|U_{\text {pn }}\right| \leq 1.1 U_{\text {nom }}$

$V U F \leq 2 \%$,

for $>95 \%$ of all weekly 10 min intervals, and

$0.85 U_{\text {nom }} \leq\left|U_{p n}\right| \leq 0.9 U_{\text {nom }}$,

for $<5 \%$ of all weekly 10 min intervals. The inverse sequence VUF is defined as the ratio between the inverse and direct component as follows:

$V U F_{-}[\%]=\frac{\left|U_{\text {inverse }}\right|}{\left|U_{\text {direct }}\right|} \times 100$.

There are many voltage and current unbalance definitions for three-phase three-wire systems which assume that zero sequence current is negligible since it cannot flow through three-wire systems. However, the zero sequence unbalance has significant impact in the three-phase four-wire systems which are common in the distribution systems, and should be taken into consideration when assessing the unbalances in such cases. So, the zero sequence VUF can be defined as the ratio between the zero and the direct component as follows:

$V U F_{0}[\%]=\frac{\left|U_{\text {zero }}\right|}{\left|U_{\text {direct }}\right|} \times 100$.

Current unbalance factors $C U F_{-}$and $C U F_{0}$ are defined analogously to VUF definitions shown in Eqs. (5) and (6). In order to combine the impact of both $V U F_{-}$as well as $V U F_{0}$, i.e. to combine 
Eqs. (5) and (6), [25] proposed a new root mean square VUF defined as:

$$
V U F_{\text {rms }}[\%]=\frac{\sqrt{\left|U_{\text {zero }}\right|^{2}+\left|U_{\text {inverse }}\right|^{2}}}{\left|U_{\text {direct }}\right|} \times 100,
$$

which was found as the best fitted variable for assessing unbalance consequences, and can be applicable both for three-wire and fourwire systems. Hence, the authors will use all three definitions to evaluate the impact of the proposed control on the voltage unbalances.

\section{Methodology}

With increasing penetration of small scale energy resources on the distribution level, the net impact of many generators reaches a level where the power quality is significantly affected. Low voltage distribution grids typically have the $X / R$ ratio between 0.2 and 2 [23] meaning that the reactive power contribution to voltage variations should not be ignored. For comparison, [26] reports typical X/R ratio to be between 6 and 9 for high voltage grids. Generally, as illustrated in Fig. 1 and seen in Eq. (8), offsetting the reactive current $I_{i}$ from the voltage source with $U_{1}$ has an impact on the voltage magnitude $U_{2}$ at the end of the line with the impedance $(R+j X)$.

$\left|U_{2}\right|=\sqrt{\left|U_{1}\right|^{2}-\left|I_{i} R+I_{r} X\right|^{2}}-\left|I_{r} R\right|+\left|I_{i} X\right|$

Nowadays, there are already commercially available PV inverters which can modulate the power factor and provide inductive reactive power by using excess PV inverter capacity, which is even requested by some standards $[27,28]$. Similarly, the principle can be applied to electric vehicles which are equipped with advanced power electronics [29], in order to mitigate the induced voltage problems.

\subsection{Voltage enhanced EV reactive power control}

As EVs are big loads compared to other residential loads, if they do not provide support to the grid, the DSO will be forced to employ additional units for ensuring the power quality in case of high EV penetrations resulting in the overall higher cost for the society. The EV 4-quadrant converter can be enabled to exchange the reactive power with the grid and provide voltage support. As seen in Fig. 2, the nominal converter size $S_{\text {conv }}$ and the EV active power $\left(P_{E V}\right)$ determine the reactive power bounds $\left( \pm \mathrm{Q}_{\mathrm{reg}}\right)$ within which the reactive power can be modulated $\left(Q^{*}\right)$. The complex power at the point of common connection is then defined by $S_{P C C}$.

Fig. 2(a) presents the constant power factor concept which has widely been investigated for PVs and somewhat for the EVs [23], whereas Fig. 2(b) presents the proposed enhanced voltage support with a dynamical reactive power set point. It can be seen that the proposed enhanced reactive power support has a wider operational range since the reactive power is dynamically calculated as a function of consumed active power as well as the voltage at the EV connection point, i.e., the power factor is no longer fixed but can be dynamically changed during the operation, and can be either inductive or capacitive depending on the grid status. Such reactive
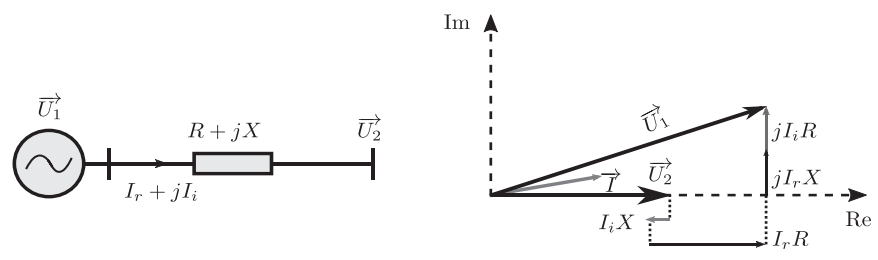

Fig. 1. Impact of active and reactive power on the voltage magnitude.
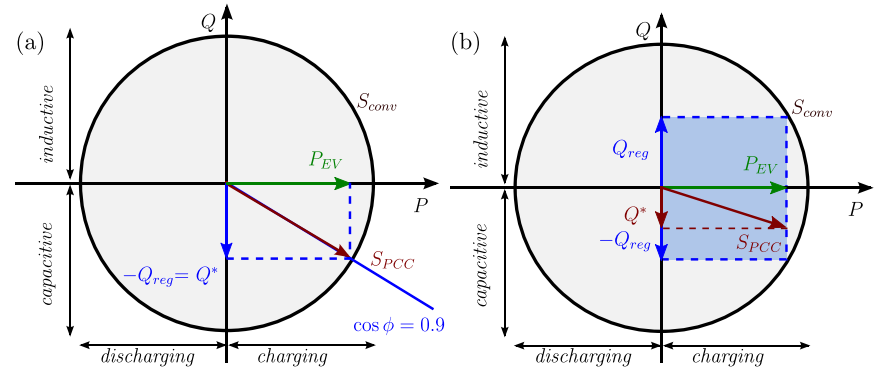

Fig. 2. 4-Quadrant EV converter operating scheme while charging for (a) constant power factor concept, and (b) proposed voltage enhanced support with dynamic power factor.

power control is autonomous with no need for external communication since an on-board controller monitors the voltage conditions during the charging process and compensates the voltage deviations by calculating the necessary reactive power. The control can adjust the EV power factor according to the local phase-to-neutral voltage measurements, instantaneous active power and predefined droop control. Not only does the proposed control mitigate the low-voltages induced by the EVs themselves, it also provides support in critical peak hours when other resources, e.g. PVs, are not active and cannot provide any support. In case of the EV charging period coinciding with other local renewable resources which inject power back to the grid leading to increased voltages even with the high EV load, the vehicle will provide inductive reactive power support potentially allowing more renewable resources to be connected. The proposed control can be used for vehicles whilst charging, but can also be expanded to the discharging period if the vehicles have V2G capability. Moreover, since the inverter is sized to provide reactive power additionally to the active power charging rate, there is no need for prioritizing between them, so the proposed control provides voltage support without affecting the state of charge, and consequently the user comfort and primary transportation purpose.

Implemented droop control, which is a function of consumed active power and the voltage at the EV connection point, can be seen in Fig. 3. Voltage limits have been set according to the Danish technical regulation for generation facilities with rated current $16 \mathrm{~A}$ per phase or lower [30]. Hence, the maximum capacitive or inductive reactive power provision occurs at 0.9 and $1.1 \mathrm{p} . \mathrm{u}$. respectively. Considering that this regulation does not specify all RPC requirements, the control has been modified according to the Italian technical standards [27] since both countries belong to the same synchronous region and therefore harmonization of regulations is expected in the future. However, the dead-band where the controller is active but provides no reactive power has been

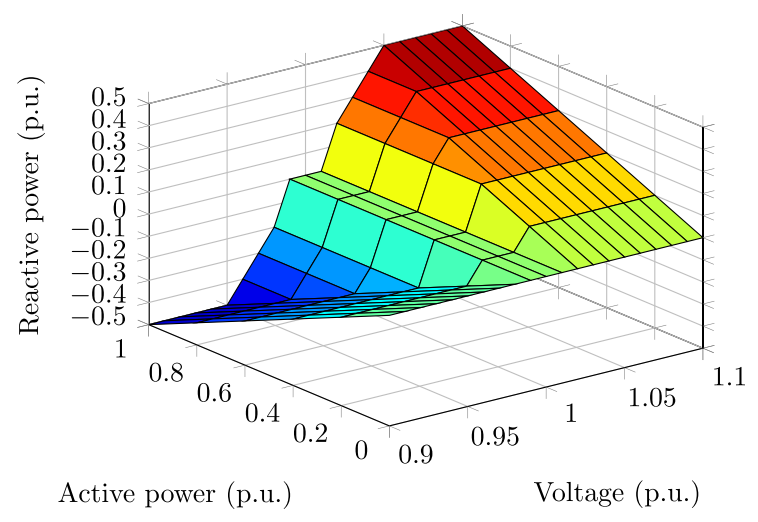

Fig. 3. Reactive power control capability of the EV converter. 
arbitrarily chosen and set to \pm 0.01 p.u. The reactive power limits are assumed to be \pm 0.5 p.u. which equals to $\pm 1.85 \mathrm{kVAr}$ and corresponds to $\cos \phi=0.9$ (ind./cap.). For comparison, commercially available PV inverters from SMA Solar Technology have the possibility to modulate the reactive power up to $\cos \phi=0.8$ (ind./cap.). Remaining RPC droop values have been obtained by linear interpolation.

Similar droop control has been investigated in [21,22], but this controller was based on the three-phase voltage measurements as the considered system was balanced. This paper proposes an EV reactive power control dependent on the single phase voltage-toneutral measurements which implies the support to more loaded phases, as well as partial mitigation of voltage unbalances caused by other units in the grid. In addition, since the neutral conductor is not grounded at the residential level and the control is based on voltage-to-neutral measurements, the proposed controller is influenced by the floating neutral point. Moreover, as reported in [31], a kick-back effect has been observed for larger amount of demand response units reacting to the same input signal due to their synchronous response, so a random term was introduced to diversify the units' behavior. Hence, short random delays have been implemented in the proposed control to represent different response times and in order for the EV controllers not to all react at the same time, which partially mitigates the short-term synchronization instability for high EV penetrations. This way the proposed controller remains a cheap and simple solution which can be implemented in all contemporary EV charging stations without the need for additional communication infrastructure for unit coordination.

\section{Test case}

The analyzed $400 \mathrm{~V}$ feeder is a real semi-urban low-voltage feeder located in Zealand, Denmark, and modeled based on the information provided by the Danish DSO, a partner in the Nikola project [32]. This feeder is radially run and connected to $10 \mathrm{kV}$ medium voltage network through a $400 \mathrm{kVA}$ distribution transformer whose secondary star point winding is directly grounded. As this is the only feeding point of the grid, the voltage source is assumed to be a swing generator with three-phase short circuit power of $10 \mathrm{MVA}$. In addition, it is assumed that the transformer's high voltage side is kept at 1 p.u. so the $\pm 10 \% U_{n}$ is completely available for the LV regulation. However, this may not be the case if part of the range is reserved for MV regulation which could impose additional need for voltage support.

As seen in Fig. 4, the 43 residential loads are three-phase grid connected through 10 nodes ( $p \in\{a, b, c\}$ ) with the common neutral conductor $(n)$ grounded only at the transformer substation. The nominal phase-to-neutral voltage $U_{n}$ equals to $230 \mathrm{~V}$. Depending on their location and consumption characteristics, the loads can be categorized in two groups: (1) Hørmarken indicated as area A, and (2) Græsmarken indicated as area B. The peculiarities of

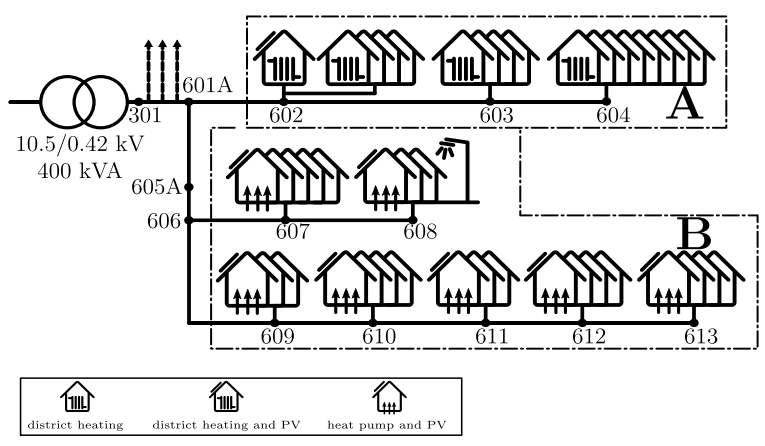

Fig. 4. Schematic overview of the observed network's topology. each group will be described later on. The feeder is composed of 13 line segments, all of the same type: Al PEX $4 \times 150 \mathrm{~mm}^{2}$ with $R=0.207 \Omega / \mathrm{km}$ and $X=0.078 \Omega / \mathrm{km}(X / R=0.37)$, which corresponds to typical low-voltage grid parameters, e.g., similar to the ones of the CIGRE European low-voltage benchmark network [26]. The distance between the households and the transformer varies between $161 \mathrm{~m}$ and $398 \mathrm{~m}$, whereas the cables are between $25 \mathrm{~m}$ and $112 \mathrm{~m}$ in length. There are three additional feeders under the same transformer station which have been represented as a single aggregated load connected to the low-voltage side of the transformer due to the lack of data per individual house.

\subsection{Residential consumption and PV production}

As already mentioned, households are divided in two groups: (1) houses in zone A which have implemented district heating and therefore lower consumption, and (2) houses in zone B which have heat pumps and consequently higher consumption during the heating period. All houses are equipped with smart meters, so individual consumption profiles are based on real metering data from March 2012 to March 2013 with an hourly sampling rate. However, due to the computational time, two characteristic weeks have been chosen for further analysis: (1) a spring week in mid-May with low consumption and high PV production resulting in the highest net power flow from the feeder to the MV grid in the observed year, and (2) a winter week with high consumption and almost no PV production resulting in the highest net power flow from the MV grid to the feeder in the same year.

Fig. 5 shows the total transformer consumption for the winter week distinguishing the observed feeder from the total load, and the average daily house consumption calculated as the mean of all consumption values at the specific hour. It can be seen that the observed feeder equals to around $40 \%$ of the total transformer load as well as that households in zone B have higher consumption due to installed heat pumps. Similarly, the same data analysis has been conducted for the observed spring week when the total consumption is much lower and the average daily profiles for the two zones are similar. Table 1 summarizes the obtained consumption values for both weeks.

The consumption values are based on the measured three-phase power flows with no insight into individual phase fractions. Since residential customers in Denmark have the three-phase connection available and there is no regulation for load connection but it
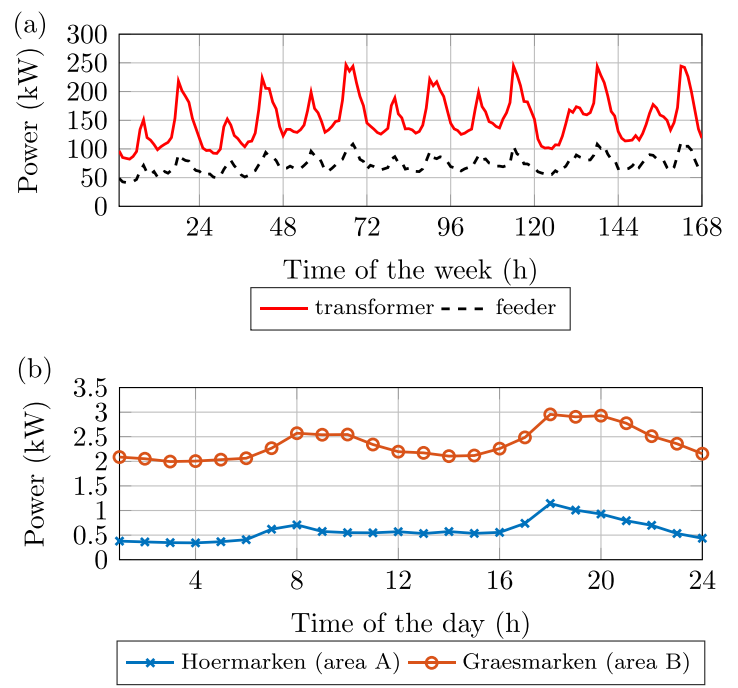

Fig. 5. (a) Total weekly and (b) average daily consumption for the observed winter week (phase distributed in ratio 50\%:25\%:25\%). 
Table 1

Consumption overview for the observed weeks.

\begin{tabular}{|c|c|c|c|}
\hline Season & $\begin{array}{l}\text { Transformer } \\
\text { weekly } \\
\text { consumption } \\
(\mathrm{kWh})\end{array}$ & $\begin{array}{l}\text { Feeder weekly } \\
\text { consumption } \\
(\mathrm{kWh})\end{array}$ & $\begin{array}{l}\text { Average daily } \\
\text { household } \\
\text { consumption } \\
(\mathrm{kWh})\end{array}$ \\
\hline Spring & 10,176 & 2,883 & $7.9 / 10.6^{a}$ \\
\hline Winter & 25,416 & 12,251 & $14.2 / 56.4^{\mathrm{a}}$ \\
\hline
\end{tabular}

a Lower value stands for area A and greater for area B.

is solely dependent on the accredited electrician making the house installation, household appliances are usually randomly phase connected. However, based on the network operator's experience, the observed grid is heavily unbalanced with most of the loads connected to phase $a$. Hence, it has been assumed that phase $a$ is loaded with $50 \%$ of the consumption, while the rest has been equally distributed among two other phases, i.e., $25 \%$ on phase $b$ and $25 \%$ on phase $c$. Additionally, the measured data does not contain the reactive power component, so a fixed power factor has been assumed for all households based on DSO's recommendation, i.e., $\cos \varphi=0.95$ (ind.).

As shown in Fig. 4, photovoltaic installations (PVs) are entirely located in area B, except of one installation located in area A. There are $27 \mathrm{PVs}$ in total: 24 installations with peak power $P=2.96 \mathrm{~kW}$ and 3 installations upgraded to $P=4.07 \mathrm{~kW}$ connected through a $3.6 \mathrm{~kW}$ or a $5.4 \mathrm{~kW}$ single phase inverter respectively. Similarly to the load distribution per phase, the PV connection points are not known either due to the lack of regulation. Hence, PVs in the model have been randomly distributed on different phases taking into consideration that the overall production per phase is approximately the same. In addition, one single PV representing aggregated production in the three remaining feeders has been added to the low-voltage side of the transformer. This production is balanced among the three phases. Besides the residential consumption, individual PV production is also measured on hourly basis for the same year. By analyzing the data for the two observed weeks, it can be easily concluded that the PV production is negligible in the winter period whereas it exceeds the consumption multiple times in the spring time. Table 2 summarizes the total PV production and average daily production per household for the observed weeks. The later has been calculated on the same principal as the average daily consumption, more precisely as the mean of all production values for the specific hour. By comparing the values for the observed feeder and the remaining three feeders, it can be concluded that most of the PVs are located in area B whereas only a small fraction of the total production comes from the remaining feeders.

\subsection{Electric vehicles}

To every household in the observed Hørmarken-Græsmarken feeder, an EV has been added resulting in 100\% penetration rate. However, looking at the transformer level, the penetration rate is around $25 \%$ since there is approximately the same amount of households under each of the four low-voltage feeders. If the penetration rate was higher and EVs were present in other feeders as well, the voltage at the low-voltage side of the transformer would decrease resulting in higher voltage deviations in the observed

Table 2

PV production overview for the observed weeks.

\begin{tabular}{llll}
\hline Season & $\begin{array}{l}\text { Transformer } \\
\text { weekly production } \\
(\mathrm{kWh})\end{array}$ & $\begin{array}{l}\text { Feeder weekly } \\
\text { production } \\
(\mathrm{kWh})\end{array}$ & $\begin{array}{l}\text { Average daily } \\
\text { household } \\
\text { production }(\mathrm{kWh})\end{array}$ \\
\hline $\begin{array}{l}\text { Spring } \\
\text { Winter }\end{array}$ & 3,404 & 3,096 & 17.0 \\
& 38 & 32 & 0.2 \\
\hline
\end{tabular}

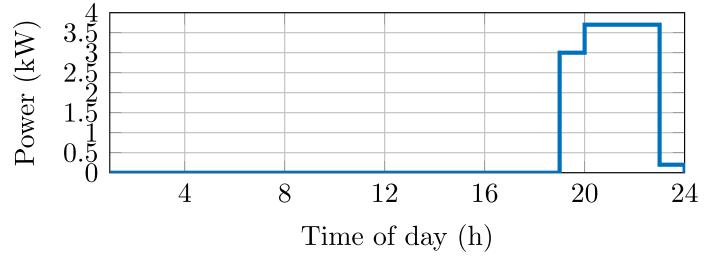

Fig. 6. Implemented single-phase EV “dumb-charging” pattern.

feeder as well. Nevertheless, the analyzed case can be seen as one of the biggest challenges for the network operator due to already high unbalanced nature of the observed grid and high local EV concentration.

Similarly to PVs, all vehicles are connected to a random single phase with overall equal number per phase. It is assumed that Mode 3 charging infrastructure [33] is used with single-phase $16 \mathrm{~A}$ connection plug. The EV charging pattern has been taken from Test-en-EV program where 184 vehicles were distributed to 1600 different Danish families over a three year period. It corresponds to an average "dumb-charging" profile which lasts for $5 \mathrm{~h}$ with total $14.3 \mathrm{kWh}$ of consumption per session, i.e., approximately $90 \%$ of the total $16 \mathrm{kWh}$ battery. Moreover, the starting time is randomly distributed between 18:45 and 19:15. Based on the same data set, [34] reports high probability (above $80 \%$ ) for a single $\mathrm{EV}$ to be home after $18: 00$, so this paper aims to assess the worst case scenario when all EVs are charging at the same time which corresponds to the peak consumption hours. In addition, several parameters will also be presented for a lower EV penetration rate of $50 \%$.

The charging process represented at Fig. 6 can be divided into three specific periods: (1) charging at the $3 \mathrm{~kW}$ rate for the first hour, (2) charging at the nominal $3.7 \mathrm{~kW}$ rate for the following $3 \mathrm{~h}$, (3) charging at $0.2 \mathrm{~kW}$ rate in the last hour. The charging efficiency is included in the charging pattern. However, since it is highly dependent on the vehicle type as well as on the chosen charging rate, lower charging efficiency would result in higher consumption implying lower voltages and need for additional voltage regulation.

\section{Results}

\subsection{Scenario overview}

This paper compares relevant network parameters for four distinctive scenarios differing in the season and RPC activation, as listed in Table 3. It is important to note that PVs are also equipped with RPC similar to the EV one which cannot be deactivated, i.e., it is always turned on and PVs are continually contributing to voltage regulation by injecting inductive reactive power whenever the production differs from zero. Nevertheless, this does not influence the reactive power provision by EVs since the activation times do not coincide. Therefore, the base case is considered to be the one with active RPC from PVs to which then EV contribution has been added.

The simulations have been made in Matlab Simulink SimPowerSystems with a variable time step of maximum $1 \mathrm{~min}$ while the household load profiles are constant for their hourly period. The conducted analysis focused on several relevant network

Table 3

Conducted simulation scenarios.

\begin{tabular}{llll}
\hline Scenario & Season & RPC by PVs & RPC by EVs \\
\hline I & Spring & On & Off \\
II & Spring & On & On \\
III & Winter & On & Off \\
IV & Winter & On & On
\end{tabular}


phase a

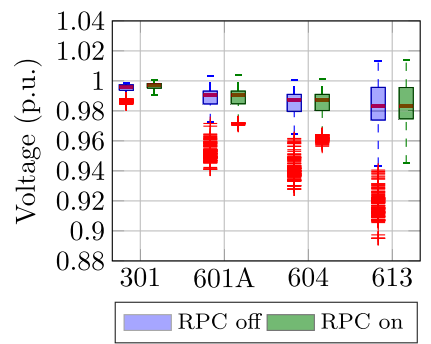

phase $b$

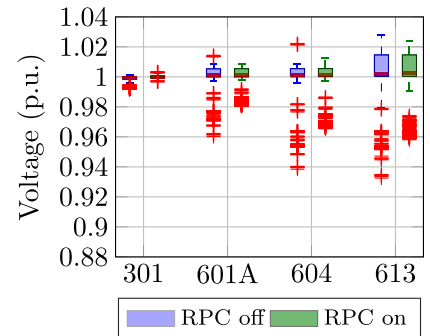

phase c

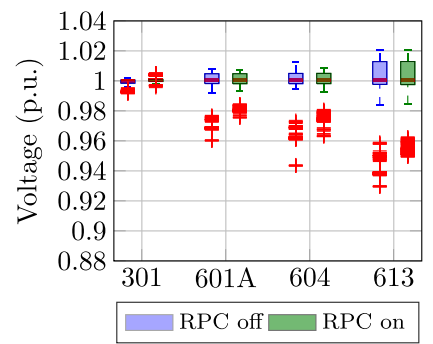

Fig. 7. Phase-to-neutral voltages at selected junction points for the spring scenarios.
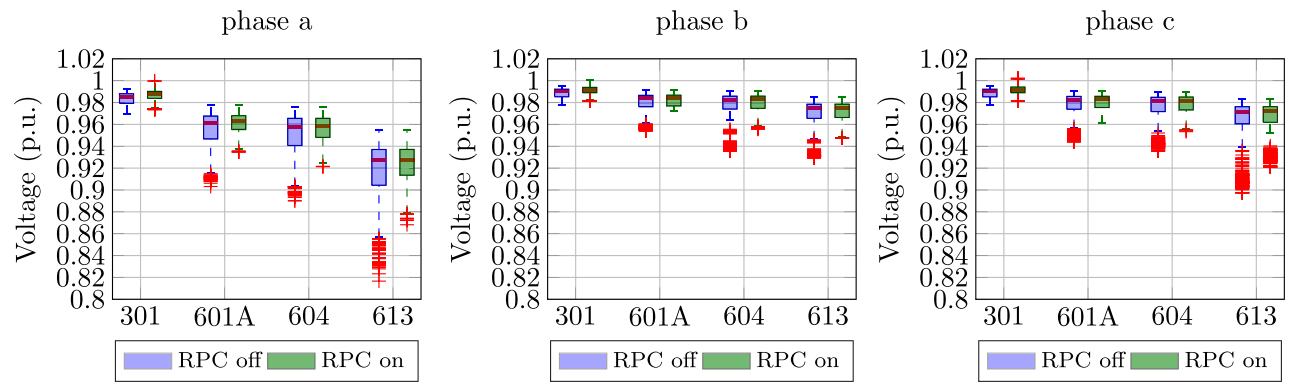

Fig. 8. Phase-to-neutral voltages at selected junction points for the winter scenarios.

(a) neutral-to-ground - spring

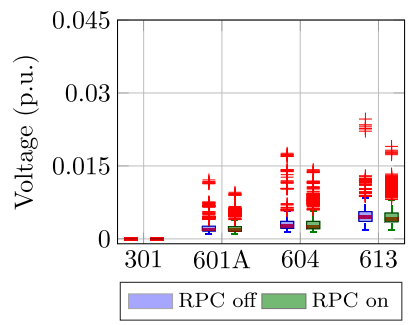

Fig. 9. Neutral-to-ground voltages at selected junction points for the spring and winter scenarios.

parameters, i.e., voltage and current magnitude, voltage unbalance factor (VUF), current unbalance factor (CUF), and active power losses which will be presented in the following subsections. The voltage magnitude has been evaluated on $10 \mathrm{~min}$ rms values for each phase-to-neutral as well as for the neutral-to- ground. VUF has been analyzed by comparing the values for each time instance, whereas active losses have been addressed by comparing the maximum phase currents and cumulative energy loss values. All of the mentioned parameters will be presented for the selected junction points, i.e., transformer low-voltage side (node 301), the beginning of the observed feeder (node 601A), and the end points of each area (node 604 for area A and node 613 for area B).

\subsection{Phase-to-neutral and neutral-to-ground voltage magnitudes}

The $10 \mathrm{~min}$ rms voltage values for spring scenarios are given in Figs. 7 and 9a, whereas the winter scenarios are presented in Figs. 8 and $9 \mathrm{~b}$. While the minimum voltage on heavily loaded phase $a$ is comparable to phases $b$ and $c$ in the spring time, it can be easily seen that the difference is much greater in the winter period since $V_{a_{\min }}$ reaches almost 0.8 p.u. at the feeder end-point. The reason lies in already high household consumption which is unevenly distributed on the phases.

Even though the EVs could be integrated in the network without causing any substantial problems to the network in the spring time,
Table 4

Phase-to-neutral voltage improvements after RPC activation.

\begin{tabular}{|c|c|c|c|c|c|c|c|}
\hline \multirow[t]{2}{*}{ Season } & \multirow[t]{2}{*}{ Node } & \multicolumn{3}{|c|}{$\Delta V_{\min }(\%)$} & \multicolumn{3}{|c|}{$\Delta \sigma_{V}(\%)$} \\
\hline & & $a$ & $b$ & c & $a$ & $b$ & $c$ \\
\hline \multirow{4}{*}{ Spring } & 301 & 0.6 & 0.5 & 0.4 & -49 & -56 & -36 \\
\hline & $601 \mathrm{~A}$ & 3.1 & 2.1 & 1.6 & -46 & -34 & -32 \\
\hline & 604 & 3.1 & 2.9 & 2.1 & -41 & -30 & -29 \\
\hline & 613 & 5.6 & 2.7 & 2.1 & -39 & -16 & -19 \\
\hline \multirow{4}{*}{ Winter } & 301 & 0.4 & 0.4 & 0.4 & -3 & -9 & -1 \\
\hline & $601 \mathrm{~A}$ & 3.5 & 1.9 & 1.8 & -47 & -51 & -44 \\
\hline & 604 & 3.5 & 2.1 & 1.9 & -45 & -43 & -41 \\
\hline & 613 & 6.3 & 1.9 & 2.6 & -44 & -37 & -31 \\
\hline
\end{tabular}

voltage support is needed for charging the same cars in the winter time. It is clear from the figures that the voltages improve after activation of RPC by electric vehicles. Not only does the $V_{\min }$ increase at all junction points and all phases, but the voltage dispersion $\sigma_{V}$ also decreases as summarized in Table 4. As anticipated, RPC has the highest influence on phase $a$ where the relative deviation is decreased twice as much than on the other two phases. However, looking at the voltage dispersion (standard deviation), the change is comparable for all three phases with the highest value of $56 \%$ occurring for phase $b$ in the spring period. Similarly, neutral-to-ground voltages are decreased from maximum $5.7 \mathrm{~V}$ to $4.4 \mathrm{~V}$ in the spring scenario, and from $6.5 \mathrm{~V}$ to $4.6 \mathrm{~V}$ in the winter one. Even though there is no regulation for neutral-to-ground values, keeping them as close as possible to zero is desired. Hence, the analyzed control is beneficial in achieving this goal.

For lower EV penetration rates, the qualitative effect of the proposed control is the same, whereas the quantitative is reduced since there is less units capable of providing voltage support. For example, in the spring case with $50 \% \mathrm{EV}$ penetration rate, the minimum phase-to-neutral voltage on phase $a$ at node 613 had been increased by $2.2 \%$ compared to $5.6 \%$ in $100 \%$ EV penetration case, whereas the voltage dispersion has been decreased by $33 \%$ compared to $39 \%$.

As aforementioned, one of the benefits of the proposed EV reactive power control is more support to the more loaded phase. More precisely, for different unbalance scenarios, the vehicles will 
Table 5

Maximum EV reactive power provision per phase and respective voltage improvement for different unbalance situations in the winter scenario.

\begin{tabular}{|c|c|c|c|c|c|c|c|c|c|c|}
\hline \multirow[t]{2}{*}{ Season } & \multirow[t]{2}{*}{ Load unbalance ratio (\%) } & \multicolumn{3}{|c|}{$P_{\text {load }_{\max }}(\mathrm{kW})$} & \multicolumn{3}{|c|}{$Q_{E V_{\max }}(\mathrm{kVAr})$} & \multicolumn{3}{|c|}{$\Delta V_{\min }(\%)$} \\
\hline & & $\bar{a}$ & $b$ & c & $\bar{a}$ & $b$ & $c$ & $\bar{a}$ & $b$ & $c$ \\
\hline \multirow{3}{*}{ Winter } & $33: 33: 33$ & 133.9 & 130.3 & 133.9 & 23.7 & 21.5 & 22.7 & 3.6 & 3.3 & 3.7 \\
\hline & $40: 30: 30$ & 150.4 & 122.1 & 125.8 & 25.9 & 18.6 & 21.6 & 3.8 & 3.1 & 3.5 \\
\hline & $50: 25: 25$ & 175.1 & 109.7 & 113.4 & 25.9 & 11.8 & 22.0 & 6.3 & 1.9 & 2.6 \\
\hline
\end{tabular}

provide different amounts of reactive power at each phase as seen in Table 5 for the winter period with $100 \% \mathrm{EV}$ penetration. First of all, the data indicates that the case of equal load distribution per phase is not completely balanced, which is due to different number of houses per node, and therefore unequal distribution of EVs per each node. Therefore, the maximum reactive power provision is similar, as well as the impact on the minimum voltage raise, but it is not entirely the same for all three phases. Secondly, it is clear that as the load unbalance increases, the reactive power support on phase $a$ also increases, while the support on other two phases decreases. The same effect is seen on minimum voltage improvement which can be associated to the lower need for improving the voltages on phases $b$ and $c$. Further on, the maximum reactive power limit is reached for vehicles on phase $a$ indicating that the voltages are too low and there is need for additional support on this phase. Finally, it can be seen that in the heavily unbalanced case, the reactive power provision on phase $a$ is much higher than on the other two phases, whereas the support to phase $b$ is much less compared to the one to phase $c$. This can be explained by the fact that phase-to-neutral voltages are not completely decoupled one from each other, so supporting one phase will partially impact the other two phases due to moving of the floating neutral point. In this case, the voltage on phase $b$ rises, and because the vehicles are not completely synchronized, some of the controllers will react later and adjust the support according to the voltage which has already been impacted by the controllers on the other two phases.

However, since the reported voltage improvements are at the expense of increased reactive power and potentially increased loading, grid power losses have been analyzed and reported in Section 5.5.

\subsection{Voltage oscillations}

Fig. 10 depicts the reactive power flow at phase $c$ for one spring day, separately for the loads, PVs and EVs for a lower EV penetration of $50 \%$. Since the simulation is run with a variable time step of maximum $1 \mathrm{~min}$, short-term oscillations have been noticed due to simultaneous reaction of the RPC controllers from the PVs in the middle of the day. More precisely, as the phase $a$ controller improves the corresponding voltage, it influences the voltages on the two other phases at the same time. Similarly, the controllers on other phases try to improve the matching voltages and impact the remaining phases. Since the controllers are autonomous, they do not count for the voltage deviations made by the other controllers and therefore do not compensate the reactive power accordingly. Hence, at a certain point when the phase-to-neutral voltages come close one to each other, reactive power oscillations occur which eventually cause voltage oscillations. Similar synchronization issues have been observed with other coordinated controllers for active power provision by distributed energy resources [12]. In the $50 \% \mathrm{EV}$ penetration case, there is no oscillations for the EVs as there is no synchronization issue between them due to their lower number. As PVs and EVs do not coincide in time, the voltage at the peak time is influenced solely by the EV reactive power provision, so there is no voltage instability at that period, whereas the instability appears from the PVs in the middle of the day. Moreover, due to lower EV penetration and less available units for the voltage support, the minimum

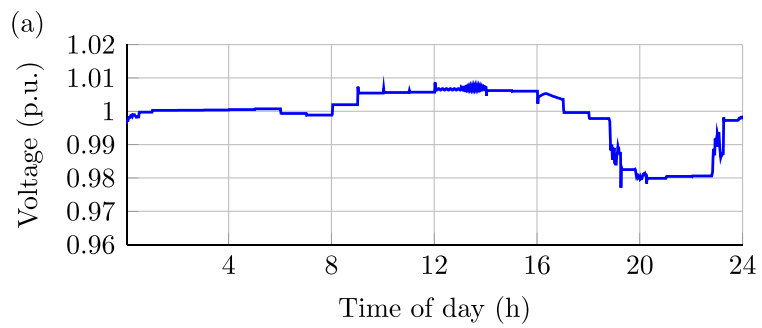

(b)

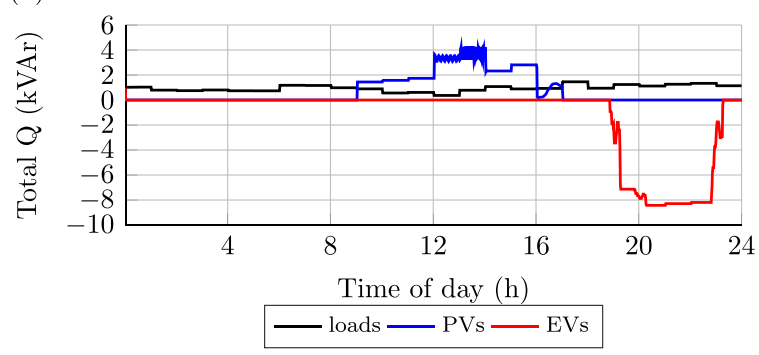

Fig. 10. (a) Phase-to-neutral voltage on phase $c$ at node 601A, and (b) total reactive power for the observed feeder's phase $c$ in case of $50 \% \mathrm{EV}$ penetration for one spring day.

phase-to-neutral voltage has been improved only by $0.33 \%$. It can be seen from Fig. 10 that EVs provide around $8 \mathrm{kVAr}$ of reactive power support which is approximately $62 \%$ of the maximum capability for 7 vehicles on phase $b$. The maximum was not achieved as phase-to-neutral voltages are low enough so that the EVs provide full reactive power support constantly.

The mentioned voltage oscillations represent a potential drawback of the dynamic reactive power control which occurs for high local EV penetration rates. An example of reactive power control of a single vehicle connected to phase $c$ can be seen in Fig. 11 for one working day of the observed winter and spring week with $100 \% \mathrm{EV}$ penetration. Random delays up to $6 \mathrm{~s}$ have been implemented in
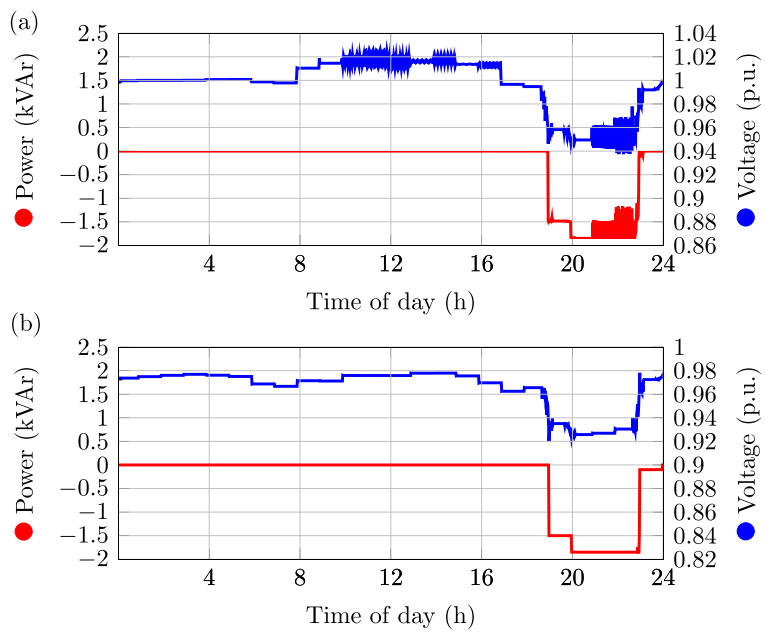

Fig. 11. Example of reactive power provision by a vehicle connected to phase $c$ at node 613 for (a) spring and (b) winter. 


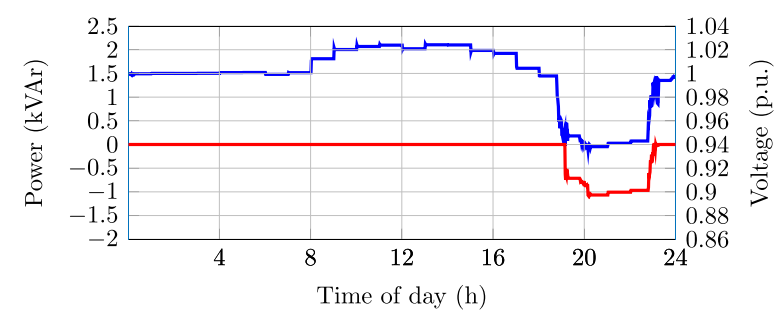

Fig. 12. Example of reactive power provision by a vehicle connected to phase $c$ at node 613 for a spring scenario with reduced droop slope.

the controllers to address this oscillation issue and diversify the EV response. Even though the delays are successful in removing oscillations for the winter period, they are not enough for avoiding them completely in the spring case. Interestingly, Fig. 11 also shows that the controller reaches the saturation limit of $1.85 \mathrm{kVAr}$ in the winter case indicating that the demand for voltage support is greater than it can be provided by the EV. There are still periods when the oscillations are present which could be resolved by implementing a moving average on the voltage measurements or by modifying the slope and maximum values for the RPC capability depending on the specific grid's parameters.

Implementing an adaptive droop slope for high EV penetrations which limits the maximum reactive power provision could be potential solution for mitigating the voltage oscillations. Fig. 12 depicts the reaction of the same vehicle shown in Fig. 11 for an adjusted droop with a reduced slope in $100 \%$ penetration scenario. It can be seen that the voltage oscillations have disappeared in this case as the reactive power provision has been limited for each unit, but the reactive power provision of the vehicle has been reduced almost by half resulting in greater voltage dispersion than in the case of the original control. However, the mentioned oscillation issues have not been thoroughly studied in this paper, so investigating an adaptive controller for different grid parameters and specific EV penetration rate is left for future work.

\subsection{Voltage unbalance factor}

Voltage unbalance factors $V U F_{-}, V U F_{0}$ and $V U F_{r m s}$ have been calculated according to (5), (6) and (7), respectively for all junction points. As expected, it was observed that voltage unbalances are higher in the winter case when the consumption is substantially greater due to the heating needs. Fig. 13 reports VUF_ values for the selected nodes in the winter period. Node 613 has been recognized as the most critical node since it is the most distant connection point in the network with the highest unbalances, and is therefore chosen as the focus point of further analysis.

Table 6 summarizes maximum VUF values at node 613 , and the time for which VUF - is not compliant with the standard [24]. Looking at the scenarios without the voltage support, it can be observed that VUF - is always below the limit during the spring period while the limit violations occur in the winter period. However, they are still within the EN50160 requirements which allow

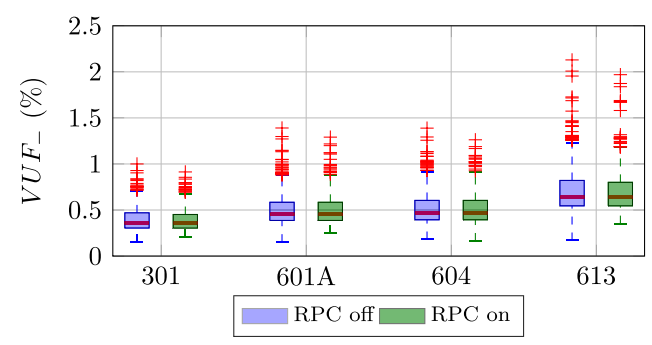

Fig. 13. VUF_ at selected junction points for the winter scenarios.
Table 6

Voltage unbalance factors at node 613 for conducted scenarios.

\begin{tabular}{llllll}
\hline Scenario & Season & $V U F_{-\max }(\%)$ & $V U F_{-}>2 \%(\mathrm{~h})$ & $V U F_{0 \max }(\%)$ & $V U F_{r m s_{\max }}(\%)$ \\
\hline I & Spring & 1.55 & 0 & 4.2 & 4.4 \\
II & Spring & 1.87 & 0 & 3.5 & 3.7 \\
III & Winter & 2.13 & 1.2 & 7.9 & 8.1 \\
IV & Winter & 1.99 & 0 & 5.6 & 5.8 \\
\hline
\end{tabular}

$5 \%$ or approximately $9 \mathrm{~h}$ of $V U F_{-}>2 \%$ in a week. On the other hand, maximum $V U F_{0}$ and $V U F_{r m s}$ are above the $2 \%$ limit well beyond the acceptable duration, especially in the winter time when the limit is almost constantly violated, mainly due to the large residential load unbalance.

By introducing droop RPC in the spring period, VUF - is slightly increased which can be explained by the fact that the direct voltage component is decreased while the inverse one remains the same. Still, both values are within the limits so it can be considered as a minor drawback in regards to voltage improvements. On the other hand, even though VUF $>2 \%$ occurs less than $1 \%$ of the time in the winter period, it is additionally decreased with RPC introduction resulting in values below $2 \%$ at all times. However, it can be noted that assessing only the inverse sequence VUF may not be good enough in the three-phase four-wire systems as the zero sequence has significant impact on the system, so both inverse and zero VUF have to taken in consideration. Even though it was found that VUF increases in some cases after RPC activation, the positive impact of the proposed control on $V U F_{0}$ and consequently on $V U F_{r m s}$ is much higher, leading to overall unbalance reduction. Despite the fact that RPC is not making the grid fully compliant with the standard, it helps to decrease the $V U F_{0}$ and $V U F_{r m s}$ values, both in magnitude as well as in duration for both winter and spring scenario. In order to further analyze the RPC contribution to unbalance mitigation, the zero sequence current unbalance factor $\left(C U F_{0}\right)$ has been calculated and reported in Section 5.5.

Moreover, this analysis has been carried out on a relatively strong network with the three-phase short circuit power of 10 MVA. In the case of a weaker grid, unbalances could be much higher resulting in additional need for voltage support. Since VUF - is highly dependent on the external grid's strength, Table 7 shows the influence of a lower three-phase short circuit power $\left(S_{k 3}\right)$ on the $V U F_{-}$for the winter scenario, and clearly indicates how the unbalances increase for weaker grids. Reactive power control in such case could be crucial for mitigating the voltage unbalances and making the grid fully compliant with the standard EN50160.

\subsection{Power losses}

A major drawback of reactive power control is potential excessive loading and therefore increased energy losses. To address this issue, Table 8 compares the maximum currents and active energy losses for conducted scenarios, as well as the zero sequence current unbalance factor $\left(C U F_{0}\right)$. It is evident from the table that the active losses throughout the spring scenarios do not increase significantly and amount to around 3.5\% even though the total reactive energy increased after RPC activation. On the contrary, maximum phase and neutral currents are significantly lower in the winter period after RPC activation leading to decreased energy losses of $0.1 \%$. The reason lies in the fact that there is inductive reactive power

Table 7

Influence of the three-phase short circuit power on the maximum $V U F_{-}$in the winter scenario.

\begin{tabular}{cll}
\hline$S_{k 3}(\mathrm{MVA})$ & $V U F_{-\max }(\%)$ without RPC & $V U F_{-\max }(\%)$ with RPC \\
\hline 5 & 4.31 & 2.89 \\
10 & 2.13 & 1.99 \\
\hline
\end{tabular}


Table 8

Maximum currents, current unbalance factor and active power losses in the observed feeder.

\begin{tabular}{|c|c|c|c|c|c|c|c|c|}
\hline Scenario & Season & $I_{a_{\max }}(\mathrm{A})$ & $I_{b_{\max }}(\mathrm{A})$ & $I_{c_{\max }}(\mathrm{A})$ & $I_{n_{\max }}(\mathrm{A})$ & $C U F_{0 \max }(\%)$ & Active losses (kWh) & Relative active losses (\%) \\
\hline I & Spring & 454 & 335 & 339 & 124 & 24.8 & 440 & 3.47 \\
\hline II & Spring & 434 & 332 & 338 & 105 & 17.4 & 444 & 3.52 \\
\hline III & Winter & 698 & 539 & 552 & 139 & 26.5 & 1008 & 3.57 \\
\hline IV & Winter & 658 & 519 & 530 & 98 & 20.4 & 972 & 3.47 \\
\hline
\end{tabular}

in the grid before the RPC implementation. Therefore, EVs firstly consume the inductive reactive power and then inject additional capacitive reactive power for voltage support. It can be concluded that RPC from EVs can be effectively used for voltage support without notably influencing the energy losses. In addition, the proposed control has positive effect on the current unbalance factor both in the spring and winter scenario, meaning that it contributes to reducing the neutral conductor current which implies partial unbalance mitigation.

\section{Conclusion and future work}

Electric vehicle employment will greatly affect future distribution networks leading to additional requirements concerning voltage regulation. On the other hand, the impact of EV charging can be substantially reduced with on-board strategies which do not require additional communication infrastructure, but solely depend on local measurements. This paper proposed a reactive power droop control for phase-wise enhanced voltage support which can be easily implemented with existing EV electronics and can be used for voltage support while charging regardless of the EV location and phase connection.

The proposed control was tested on a real Danish low-voltage grid, and the results show that voltage dependent reactive power control positively affects voltage conditions and supports high EV penetration rates in highly unbalanced low-voltage grids. Even though the tested grid is not fully compliant with EN50160 standard after RPC activation, the proposed control eliminates voltage magnitudes below 0.86 p.u. on all phases in both heavily and less heavy loaded scenarios. Considering that the grid is highly unbalanced, RPC provides great improvements since the minimum voltage is increased up to $6.3 \%$ depending on the season and phaseto-neutral voltage dispersion has been reduced up to $56 \%$. Short term voltage oscillations have been noted for high EV penetration rates due to simultaneous controllers' reactions, but have been partially alleviated by implementation of random delays. In addition, such oscillations could be overcome by implementing an adaptive droop depending on the EV penetration rate, and specific system parameters and measurements. The proposed control has also been tested for a lower EV penetration rate when there are no synchronization issues. It was concluded that the controllers' qualitative impact is the same, whereas the quantitative one changes due to less available vehicles.

The paper also addresses the impact of the proposed control on grid unbalances. It was noted that inverse voltage unbalance factor can slightly increase in some cases, but the proposed control reduces $V U F_{0}$ as well as $C U F_{0}$ in all scenarios. EVs provide unequal reactive power to different phases resulting in reduction of neutral conductor current as well as partial mitigation of the unbalances caused by residential loads. In weaker grids where the unbalances are higher, such control could be crucial for integration of high EV amounts without additional grid reinforcement. Considering that RPC introduces potential increased loading due to increased reactive power, energy losses have been addressed in the study. It is concluded that voltage improvements are much higher than the side effects of additional loading since not only that the losses are marginally increased in the spring scenarios, but they are even decreased in the winter scenario due to the local consumption of already existing inductive reactive power.

If EVs do not provide support to the grid, the DSO will be forced to employ additional units for ensuring the power quality in case of high EV penetrations resulting in overall greater cost for the society. Droop parameters of the proposed reactive power controller can be easily changed depending on specific distribution grid making reactive power control applicable to any location and scalable for larger areas. Given the considered benefits, reactive power capability for EV chargers should be included in future grid compliance regulations, similarly to the current requirements for conventional power plants or PVs in countries with high penetration rates. Future work includes evaluating the RPC influence on short-term dynamics including finding the optimal slope for different grid parameters and specific EV penetration rate to avoid voltage oscillations, as well as investigating Mode 3 charging infrastructure with higher charging power.

\section{Acknowledgements}

This work is supported by the Danish Research Project "NIKOLA - Intelligent Electric Vehicle Integration" under ForskEL kontrakt nr. 2013-1-12088. More information on www.nikolaproject.info.

\section{References}

[1] J.P. Lopes, N. Hatziargyriou, J. Mutale, P. Djapic, N. Jenkins, Integrating distributed generation into electric power systems: a review of drivers, challenges and opportunities, Electr. Power Syst. Res. 77 (9) (2007) 1189-1203.

[2] K. Clement-Nyns, E. Haesen, J. Driesen, The impact of vehicle-to-grid on the distribution grid, Electr. Power Syst. Res. 81 (1) (2011) 185-192.

[3] S. Habib, M. Kamran, U. Rashid, Impact analysis of vehicle-to-grid technology and charging strategies of electric vehicles on distribution networks - a review, J. Power Sources 277 (2015) 205-214.

[4] Dansk Energi, Dong Energy, Energinet.dk, Analysis No. 5 - Scenarios for the Deployment of Electric Vehicles, Tech. Rep., 2013.

[5] M. Coppo, R. Turri, M. Marinelli, X. Han, Voltage management in unbalanced low voltage networks using a decoupled phase-tap-changer transformer, in: 2014 49th International Universities Power Engineering Conference (UPEC), 2014.

[6] J. García-Villalobos, I. Zamora, J.I. San Martín, F.J. Asensio, V. Aperribay, Plug-in electric vehicles in electric distribution networks: a review of smart charging approaches, Renew. Sustain. Energy Rev. 38 (2014) 717-731.

[7] W. Kempton, J. Tomić, Vehicle-to-grid power implementation: from stabilizing the grid to supporting large-scale renewable energy, J. Power Sources 144 (2005) 280-294.

[8] M. Gonzalez Vaya, G. Andersson, Centralized and decentralized approaches to smart charging of plug-in vehicles, in: 2012 IEEE Power and Energy Society General Meeting, 2012

[9] P. Richardson, D. Flynn, A. Keane, Local versus centralized charging strategies for electric vehicles in low voltage distribution systems, IEEE Trans. Smart Grid 3 (2) (2012) 1020-1028.

[10] H. Liang, B.J. Choi, W. Zhuang, X. Shen, Stability enhancement of decentralized inverter control through wireless communications in microgrids, IEEE Trans. Smart Grid 4 (1) (2013) 321-331.

[11] C. Battistelli, L. Baringo, A. Conejo, Optimal energy management of small electric energy systems including V2G facilities and renewable energy sources, Electr. Power Syst. Res. 92 (2012) 50-59.

[12] J. Hu, A. Saleem, S. You, L. Nordström, M. Lind, J. Østergaard, A multi-agent system for distribution grid congestion management with electric vehicles, Eng. Appl. Artif. Intell. 38 (2015) 45-58.

[13] F. Soares, P.R. Almeida, J.P. Lopes, Quasi-real-time management of electric vehicles charging, Electr. Power Syst. Res. 108 (2014) 293-303.

[14] O. Sundstrom, C. Binding, Flexible charging optimization for electric vehicles considering distribution grid constraints, IEEE Trans. Smart Grid 3 (1) (2012) 26-37. 
[15] I. Sharma, C. Canizares, K. Bhattacharya, Smart charging of PEVs penetrating into residential distribution systems, IEEE Trans. Smart Grid 5 (3) (2014) 1196-1209.

[16] N. Leemput, F. Geth, J. Van Roy, A. Delnooz, J. Buscher, J. Driesen, Impact of electric vehicle on-board single-phase charging strategies on a Flemish residential grid, IEEE Trans. Smart Grid 5 (4) (2014) 1815-1822.

[17] S. Weckx, J. Driesen, Load balancing with EV chargers and PV inverters in unbalanced distribution grids, IEEE Trans. Sustain. Energy 6 (2) (2015) 635-643.

[18] M. Kisacikoglu, M. Kesler, L. Tolbert, Single-phase on-board bidirectional PEV charger for V2G reactive power operation, IEEE Trans. Smart Grid 6 (2) (2015) 767-775.

[19] J. Fernandez, S. Bacha, D. Riu, H. Turker, M. Paupert, Current unbalance reduction in three-phase systems using single phase PHEV chargers, in: 2013 IEEE International Conference on Industrial Technology (ICIT), 2013, pp. 1940-1945.

[20] L. Carradore, R. Turri, Electric vehicles participation in distribution network voltage regulation, in: 2010 45th International Universities Power Engineering Conference (UPEC), 2010.

[21] K. Knezović, M. Marinelli, R. Moller, P. Andersen, C. Traeholt, F. Sossan, Analysis of voltage support by electric vehicles and photovoltaic in a real Danish low voltage network, in: 2014 49th International Universities Power Engineering Conference (UPEC), 2014.

[22] K. Knezović, M. Marinelli, P. Andersen, C. Traeholt, Concurrent provision of frequency regulation and overvoltage support by electric vehicles in a real Danish low voltage network, in: 2014 IEEE International Electric Vehicle Conference (IEVC), 2014.

[23] N. Leemput, F. Geth, J.V. Roy, J. Büscher, J. Driesen, Reactive power support in residential LV distribution grids through electric vehicle charging, Sustain. Energy Grids Netw. 3 (2015) 24-35.
[24] H. Markiewicz, A. Klajn, Voltage Disturbances Standard EN 50160, 2004

[25] M.T. Bina, A. Kashefi, Three-phase unbalance of distribution systems: complementary analysis and experimental case study, Int. J. Electr. Power Energy Syst. 33 (4) (2011) 817-826

[26] K. Strunz, N. Hatziargyriou, C. Andrieu, Benchmark systems for network integration of renewable and distributed energy resources, in: Cigre Task Force C 6, 2009, 04-02.

[27] Italian Reference Technical Rules for Technical Standard CEI 0-21, Connection of Active and Passive Users to the LV Electrical Utilities, Milano, 2012.

[28] German Technical Standard VDE-AR-N 4105, Power Generation Systems Connected to the Low-Voltage Distribution Network, FNN Forum Netztechnik/Netzbetrieb im VDE, 2011.

[29] R. Kohrs, K. Dallmer-Zerbe, M. Mierau, C. Wittwer, Autonomous reactive power control by electric vehicles, in: 2014 IEEE PES Innovative Smart Grid Technologies Conference Europe (ISGT-Europe), 2014.

[30] Energinet.dk, Technical Regulation 3.2.1. for Electricity Generation Facilities With a Rated Current of 16 A Per Phase or Lower, 2011.

[31] X. Han, H. Bindner, H. Hansen, K. Rasmussen, P. Cajar, Y. Ding, D. Tackie, Identification of Kick-Back from Normal Situations due to Activation of Flexible Demand, iPower Consortium, 2014.

[32] P. Andersen, M. Marinelli, O. Olesen, C. Andersen, G. Poilasne, B. Christensen, O. Alm, The Nikola project intelligent electric vehicle integration, in: 2014 IEEE PES Innovative Smart Grid Technologies Conference Europe (ISGT-Europe), 2014.

[33] IEC 61851, Electric Vehicle Conductive Charging System - Part 1: General Requirements, 2010.

[34] A. Pedersen, A. Aabrandt, J. Ostergaard, B. Poulsen, Generating geospatially realistic driving patterns derived from clustering analysis of real EV driving data, in: 2014 IEEE Innovative Smart Grid Technologies - Asia (ISGT Asia), 2014, pp. 686-691. 